\title{
The Training of Teaching Assistants in Canadian Universities: A Survey and Case Study
}

\section{La formation des lecteurs aux universités Canadiennes: Une enquête et un dossier}

\author{
RONALD W. MARX, JOHN F. ELLIS, and JACK MARTIN*
}

During the last decade, teaching effectiveness at universities in North America has experienced increased attention. Interest has swung back and forth between an almost exclusive concern about the content of instruction to an over-emphasis on process over content. Fueled by fires of student discontent at first, and tightening financial support for universities later, the improvement of university teaching is now becoming institutionalized. Evidence of this can be found, most prominently in Canada, in the establishment of organizations such as the Ontario Universities Program for Instructional Development, and of programmes offered by the Centre for Learning and Development at McGill University.

Most efforts to improve instruction have focused on one, or a combination of three areas. First, many innovations have focused on changes in curriculum design, in many cases incorporating new technologies such as computer-assisted instruction or audiotutorial methods. A second thrust is the now widespread practice of students rating instructional performance. In fact, many universities have adopted the use of student rating forms, and require favorable ratings or other evidence of good teaching for positive tenure and promotion decisions. The use of student rating forms has been the subject of considerable debate, with Murray (1977) supporting their qualified use, and McKeachie and Kulik (1975) and Wittrock and Lumsdaine (1977) looking on them with even greater reservation. The third focus has been to improve instruction by teaching university professors to be better teachers. These range from yearly seminars on teaching, such as those offered by the University of New Brunswick, to more intensive courses on skills of teaching and techniques for analyzing teaching, such as the courses offered by the University of Manitoba.

* Faculty of Education, Simon Fraser University 
Much university teaching, however, is not performed by professors. For example, at Simon Fraser University over 300 teaching assistants are employed each semester to teach about 1200 tutorial groups or labs. Many other universities also make significant use of teaching assistants. A substantial effort is being directed toward improved instructional competence of professors but what is being done for teaching assistants? No doubt some of them are working in the aforementioned innovative curricula, others are receiving feedback from student ratings (and are wondering what to do with the information), and hopefully, still others are participating in the wide range of workshops and courses on university teaching.

We know virtually nothing about the competence of teaching assistants as a group. In the best conditions, students are usually selected for this task on the basis of their subject matter competence. In the worst situations, they are selected and placed into teaching or tutoring roles simply because they need financial support and are available. The one study of the effectiveness of teaching assistants (Macomber \& Siegel, ${ }^{*}$ ) has shown that they were at least as effective as professors teaching similar students. But this one study is not sufficient evidence upon which to base generalized statements about the instructional effectiveness of teaching assistants.

Similarly, we know very little about how teaching assistants are trained other than in their academic discipline. Generally, it seems that departments, and usually professors, are charged with the responsibility of training and supervising teaching assistants. These experiences are of variable quality and range from non-existence to rather intense seminars such as those conducted at the Nova Scotia College of Art and Design.

Two issues, then, warrant investigation. First, what is the status of efforts to train teaching assistants in Canada? Second, what evidence is available regarding the effectiveness of training? We will present data addressing both of these matters. Relating to the first, we report a survey of the efforts of all Canadian colleges and universities to train teaching assistants. With regard to the second issue, we discuss the Simon Fraser University Teaching Assistant Training Programme, focussing upon the components of instruction and some representative data from an evaluation of that programme.

\section{The Training of Teaching Assistants in Canada}

While there have been some publications dealing with improving teaching effectiveness in Canadian universities (e.g., Sheffield, 1974), there are few reports that specifically focus on teaching assistants (see Anderson \& Pascal, 1970, for an exception). Evidence concerning the existence of programmes to train teaching assistants is useful not only to document such such efforts, but also to assist those who may wish to develop programmes. Consequently, a modest survey was conducted in an attempt to gather information on the existence and nature of training programmes for teaching assistants in Canadian universities.

Procedure. Letters were sent to the academic vice-president (or equivalent administrator) in each Canadian college and university listed in Universities and Colleges of Canada

\footnotetext{
* F.G. Macomber and L. Siegel, Final report of the experimental study in instructional procedures. Oxford, Ohio: Miami University, 1960.
} 
(Statistics Canada, 1975). The letter requested information regarding efforts made to improve the effectiveness of instruction, particularly with respect to teaching assistants.

Results. Responses were obtained from 40 of the 65 institutions in the sample, which was a return rate of $62 \%$. Twenty-seven of the institutions which responded either did not employ teaching assistants (two cases), or did not have a programme for the training of teaching assistants ( 25 cases). Table 1 shows the nature of the training programmes in the 13 institutions that reported either the existence of a programme or one in preparation (including the programme at Simon Fraser University).

As indicated in Table 1, the predominant forms of TA training are seminars and workshops, which usually involve between 15 and 20 hours of instruction and discussion. The formats vary widely, from the self-instructional programmes at McGill, to the labor intensive courses at Manitoba, which have a ratio of less than five participants to each instructor. In most cases participation is voluntary and rarely receives course credit. The Simon Fraser programme seems to be the only one that pays TAs for participating by reducing teaching contact hours commensurate with the number of hours of programme participation.

It is unclear exactly what kind of instruction takes place from the documentation made available to us, in many cases, the formats suggest that the predominantly verbal forms of instruction that generally are found in universities are used for TA instruction. Thus, even though much teaching can be considered skilled behavior, and hence can be improved through practice, much TA training deals with the what of teaching rather than the how. No doubt the assumption behind such training, which is in many respects justifiable, is the knowledge of instructional principles can be translated into practice by TA's, and is more generalizable than specific skill training.

The results of this survey indicate that across the country a considerable effort is being made to improve the effectiveness of instruction generally, and, more specifically, to improve the teaching of TAs. To date, however, we have very little documented evidence concerning the effectiveness of these efforts and their impact on undergraduate education. It is to this question that we now turn.

\section{The Simon Fraser University Programme}

The Simon Fraser University Teacher Assistant Training Programme (TAT) has been in operation for four years. Over 175 TAs have received training, and the enrollment for 1978-79 is about 50. The Dean of Graduate Studies has administrative responsibility for the Programme and the Faculty of Education designs and provides the instruction. This latter feature is somewhat unusual, since most other programmes are inter-faculty, even though some (e.g., University of Manitoba) are organized by faculties of education.

Training. The Teaching Assistant Training Programme consists of 15 hours of instruction distributed over five evening sessions of three hours each. The objectives of the Programme are to teach the participants how to: (1) incorporate principles of learning in the design of instruction; (2) define, state, and use behavioral objectives in planning and delivering instruction; (3) develop valid and reliable measure of learning; (4) plan and conduct effective discussion groups or laboratory sections; and (5) be sensitive to ethical and moral dilemmas in teaching. 
Table 1

Characteristics of Training Programmes in Canada

Dalhousie

Guelph

Laurentian

Manitoba

McGill

Montrea]
Seminars on general teaching techniques for faculty and graduate students

Idea exchange for innovative practices

Clearinghouse for teaching resources

Bring specialists to campus to assist with specific programmes

Numerous curriculum development projects

Training TA's to develop materials for Personalized System of Instruction (PSI) Information not available

Courses for professors and $\mathrm{TA}^{\prime} \mathrm{s}$ on: conmumication skills, course construction, observation of teaching, questioning techniques

Series of self-instructional modules (with consultants available) on instructional principles. Eight modules are currently available (e.g. designing materials, leading discussions, etc.)

Workshops, seminars, and consultants available on topics such as course planning, evaluation, teaching (unclear if available to TA's) 
Table 1 (con't)

Institution

Characteristics of Programme

New Brunswick

Saskatchewan

Simon Fraser

Toronto

Waterloo

Western Ontario

Wilfred Laurier

York
Annual Effective Teaching Institutes (unclear if TA's attend)

Twenty hour workshop for TA's and sessional lecturers; topics such as course planning, teaching modes, etc.

Workshops for TA's on instructional principles

(principles of learning, evaluation, leading discussions, etc.)

Course for credit in Theory of Tutoring for

final year students and TA's

TA course in Department of Physiology

Summer seminars for TA's now in preparation

Workshops and seminars for faculty on teaching

and curriculum development

TA project to begin in Fall, 1977

Workshops and seminars for faculty and TA's

Development of Teaching Skills Programme for

faculty and TA's

Content has been relatively unchanged but instructional procedures have undergone revision each year, based primarily on feedback from the participants. What follows is a description of the Programme as it appeared in the 1976-77 academic year.

The first session covered five basic principles of learning. The class started off with a general discussion of "good" and "bad" teachers, and the roles of skilled behavior and personality in effective teaching. Following this, discussion focused on five principles to be considered when designing and delivering instruction. First, instruction must have meaning for the learner. Second, activity and relevant practice needs to be provided. 
Third, students must receive prompt and informative feedback concerning the quality of their responses and assignments. Fourth, variability among students must be acknowledged and instruction and assignments modified accordingly. Fifth, teachers must consider differences in student motivation - making instruction engaging and challenging. Both inductive and deductive teaching approaches were used in this session and an attempt was made on the part of the instructor to model a variety of desirable teacher behaviors.

The second session dealt with the planning of instruction and the stating of behavioral objectives. The first part of the class was devoted to a presentation of behavioral objectives, including a discussion of the difference between course outlines and behaviorally stated objectives for student learning. In the second half of the lesson the participants wrote three behavioral objectives and discussed them in small groups of three or four people. During this small group activity, each group generated three advantages and three disadvantages to the use of behavioral objectives. These formed the basis of the discussion which followed in the large group.

The third meeting dealt with principles and techniques of evaluation. Concepts central to the process of evaluation were described, discussed, and illustrated. These included: measurement and evaluation; reliability and validity; and objectivity and subjectivity. Various types of test items were examined and discussed and the advantages and disadvantages of each were cited. The relationship of evaluation to both instructional objectives and instructional procedures was stressed.

The fourth session considered techniques and problems in leading discussion groups and working in laboratories. The first part of the lesson was a didactic presentation which distinguished between specific teaching skills and more general strategies of teaching. The participants discussed the skills required, for example, to enhance participation in discussion groups, to make effective use of questions, and to deal with obstreperous students. In the secon part of the meeting, the participants broke into small groups and discussed the role of the TA in the seminar and laboratory setting. The session concluded with a group discussion based on the roles defined in the smaller groups.

The last meeting started off with a visit from the Dean of Graduate Studies who led a discussion on the general problems of graduate studies and the relationship between graduate student obligations and teaching assistant responsibilities. The second half of the session was devoted to discussion of some ethical dilemmas with which teaching assistants may find themselves confronted. For example, what does the TA do when the professor appears incompetent, or when students court the TA with favors?

Evaluation of the Programme. Detailed presentation of the design of the evaluation and results of the Programme can be found in Marx, Martin, Ellis, and Hasell (1978) and Martin, Marx, Hasell, and Ellis (1978). Highlights of the results of an evaluation of the 1976-77 Programme are presented here.

Four groups of teaching assistants participated in the 1976-77 Programme. All TAT participants were selected by their respective departments. Two groups (one of 21 , the other of 12) attended the seminars in the first half of the fall, 1976, semester. The third group, with 16 teaching assistant, undertook their training in the second half of that semester. The fourth group participated during the first half of the spring, 1977, semester and had an enrollment of 17. Participants were assigned to the first two groups on the 
basis of their course schedules. Three departments, Economics and Commerce, Psychology, and Biological Science agreed to have their TAs participate in group three, and group four was formed by nomination from the departments. In addition, a control group of 18 subjects, stratified by faculty (Arts, Interdisciplinary Studies, and Science) and previous teaching experience, was randomly selected from the rest of the teaching assistants at the University.

A wide variety of measures were used to assess the effectiveness of the training. First, a random sample of participants, stratified by faculty, was interviewed within two weeks after completing the Programme. The inverview consisted of a number of closed and open ended questions concerning the quality of instruction in, and administration of the Programme. Second, all TAT participants and controls responded to an inventory relating to attitudes toward teaching, learning, students, and the Faculty of Education and TAT Programme. Third, the students of a sample of TAT participants and controls completed a paper and pencil measure of their perceptions of their respective TA's attitudes and teaching behavior, and their own attitudes toward the class and the quality of the TA's instruction. Fourth, final course grades of the students of a small sample of TAT participants were compared to the grades of students of other TA's teaching in the same multisection, undergraduate courses.

Results of the evaluation. The participants who were interviewed thought that the Programme to be less valuable had previous teacher training, usually associated with careers prior to undertaking graduate work. About half of the interview sample said that the Programme was not what they had expected, but rather far exceeded their initial expectations. Most of this subsample of TATs had expected the Programme to be overly simplistic and to be irrelevant to the demands placed on them in their course of their work. After the completion of the Programme, this group had generally concluded that the content was interesting, challenging and helped them execute their duties as TAs. Perhaps the most surprising result of the interview was the response to the question asking if the departments were providing additional help beyond the TAT Programme. Only six of the 38 participants who were interviewed (16\%) stated that they had received such help, and only two of these said that the additional help related to the training in the Programme. We found this result surprising because even though departments had not been required to collaborate in this way it had been suggested to them several times.

The attitudes of the participants and controls were assessed immediately after the Programme and again at the end of the spring, 1977, semester - a delay ranging from 2 to 6 months for TATs. The scale assessed attitudes toward the TAs' own teaching, their students, their academic discipline, their own learning, their desire to improve their own teaching, the Faculty of Education, and the TAT Programme. There were no systematic differences between the TAT groups and the control group; nor were there systematic differences favoring experienced TAs over those who had no previous teaching experience, although the TAs without previous teaching experience had significantly more positive attitudes toward their students.

At the end of the fall semester, 1976, students of a subsample of participants and controls responded to a questionnaire soliciting their attitudes and perceptions of their TA's teaching. Also, at the end of the spring semester, 1977, the same data were collected from students of all participants and controls. The most important result from analyses 
of these data was that the students of TAT participants, compared to students of control teaching assistants, perceived their TAs as better tutorial leaders and as more willing to improve their teaching.

There were statistically significant differences between student perceptions of TAs who were in the sciences compared to TAs in the arts, regardless of whether they were TAT participants or controls. Science students saw their TAs making better use of instructional materials, more adequately tying objectives to evaluation, and having better attitudes toward their academic discipline than did students of arts TAs.

Finally, in spring, 1977, final course grades were obtained from eight multisection undergraduate courses which employed at least one TA who had participated in TAT and one who had not. Tutorial groups led by TAT participants were compared to their untrained colleagues' groups. Of the eight comparisons, only one was statistically significant, and this favored the TAT participant. The control teaching assistant for this analysis were not the same as the randomly selected controls for the other sources of data. These controls contributed data to the study due to the fact that they were working in one of the multisection courses whose professors volunteered and were able to obtain useable data. Control TAs in this group had an average of 3.5 semesters of experience as TAs, while the TAT participants in this part of the evaluation had an average of .6 semesters of TA experience. One could conclude that the TAT Programme was unable to match or exceed any beneficial effects of the "school of hard knocks."

\section{Conclusions}

A modest survey of Canadian colleges and universities has shown that a number of institutions have established programmes designed to improve the quality of instruction. A number of these institutions design programmes either specifically for teaching assistants, or for teaching assistants jointly with other members of the instructional staff. This will come as welcome news to those who believe that universities have little interest in improving the quality of their teaching. Nevertheless, if one were to extrapolate from our $62 \%$ response rate, only about one-third of the colleges and universities of Canada mount such programmes. If one made a more conservative estimate and assumed that a non-return implies the lack of a training programme, the percentage of institutions offering programmes drops to $20 \%$.

If it can be assumed that future university professors are recruited from the ranks of present teaching assistants, how do the bulk of these future professors learn to teach? Perhaps, as Anderson and Pascal (1970) imply, many are not taught how to teach. They acquire a professorial position through disciplinary expertise, and hopefully will learn how to teach by a process of trial and error. One could ask, as do Anderson and Pascal, why we settle for this at the university level while we would never accept it for lower levels of schooling.

The Simon Fraser University Teaching Assistant Training Programme was presented as an example of one procedure for overcoming this lacuna in efforts to improve the effectiveness of university instruction. The results of the evaluation of the Programme suggest that efforts such as TAT are likely to meet with success. While there are obvious problems of substance and administration associated with such efforts, their potential for improving the quality of undergraduate education in our universities is considerable. In addition, programs such as TAT have a valuable side-effect: they make explicit an institution's concern for and commitment to quality instruction. The evidence in favor of teaching 
assistant training is significant. Undergraduates perceive trained teaching assistants as being better tutorial leaders than untrained. TAs. Additionally, undergraduates believe that trained teaching assistants are more willing to work at the improvement of their teaching and have a better attitude toward teaching. Along with the finding that trained teaching assistants with very little experience in their roles are at least as effective as untrained, but experienced, teaching assistants, the weight of evidence in favor of such training is clearly accumulating.

Obviously there are a multitude of questions to be answered about training teaching assistants in general and about improving our programme in particular. We have no clear idea which elements of the training are the most or least effective. We have become increasingly convinced that specific practice of teaching skills (Travers, 1973) is more effective strategy than discussion and, consequently, we will incorporate more of this activity into the Programme, Further, through our interviews we have found that teaching assistants working in science laboratories have found certain parts of the Programme inappropriate to their needs. As a consequence we are going to redesign portions of the Programme.

Beyond the substantive problems of instruction there are methodological problems associated with researching and evaluating teaching in higher education. Many of these problems mirror issues in research on teaching at other levels (Winne \& Marx, 1977). Other problems, such as the use of student rating forms as criteria of teaching effectiveness (Martin, Marx, Hasell, \& Ellis, Note 3; McKeachie \& Kulik, 1975; Wittrock \& Lumsdaine, 1977), are more uniquely associated with higher education. Hopefully, with the accumulation of empirical studies of teaching in higher education, both substantive and methodological problems will begin to be solved.

\section{REFERENCES}

Anderson, G.J., \& Pascal, C.E., "Training the graduate student teacher," Leaming and Development, $1970,1(6-7), 1-4$.

Marx, R.W., Martin, J., Ellis, J.F., \& Hasell, J., "Improving the instructional effectiveness of university teaching assistants: Report I," Canadian Journal of Education, 1978, 3, (in press).

Martin, J., Marx, R.W., Hasell, J., \& Ellis, J.F., "Improving the instructional effectiveness of university teaching assistants, Report II," Canadian Journal of Education, 1978, 3, (in press).

McKeachie, W.J., \& Kulik, M.A., "Effective college teaching," in F.N. Kerlinger, ed., Review of Research in Education, vol. 3. Itasca, Illinois: Peacock, 1975.

Murray, H.G., "Limitations of student ratings of college teaching," Canadian Association of University Teachers Bulletin, 1977, April, 28.

Sheffield, E.F., ed., Teaching in the universities: No one way. Montreal: McGill-Queen's University Press, 1974.

Statistics Canada, Universities and colleges of Canada. Ottawa; Association of Universities and Colleges of Canada, 1975.

Travers, J.M.W., ed., Second handbook of research on teaching. American Educational Research Association. Chicago: Rand McNally, 1973.

Winne, P.H., \& Marx, R.W., "Reconceptualizing research on teaching," Journal of Educational Psychology, 1977, 69, 668-678.

Wittrock, M.C., \& Lumsdaine, A.A. Instructional psychology. Annual Review of Psychology, 1977, $28,417-459$. 
